\section{$\underset{\substack{\text { hommes } \\ \text { \& migrations }}}{ }$}

\section{Hommes \& migrations}

Revue française de référence sur les dynamiques

migratoires

$1324 \mid 2019$

Religion et discrimination

\title{
Emilie de Turckheim, Le Prince à la petite tasse
}

Paris, Calmann-Lévy, 2018, 216 p., $17 €$

\section{Nihad Jnaid}

\section{(2) OpenEdition \\ 1 Journals}

\section{Édition électronique}

URL : https://journals.openedition.org/hommesmigrations/8945

DOI : 10.4000/hommesmigrations.8945

ISSN : 2262-3353

\section{Éditeur}

Musée national de l'histoire de l'immigration

\section{Édition imprimée}

Date de publication : 1 janvier 2019

Pagination : 177

ISBN : 978-2-919040-44-5

ISSN : 1142-852X

\section{Référence électronique}

Nihad Jnaid, «Emilie de Turckheim, Le Prince à la petite tasse », Hommes \& migrations [En ligne], 1324 | 2019, mis en ligne le 01 janvier 2019, consulté le 08 janvier 2022. URL : http://

journals.openedition.org/hommesmigrations/8945; DOI : https://doi.org/10.4000/ hommesmigrations.8945 


\section{Émilie de Turckheim}

\section{Le Prince à la petite tasse}

Paris, Calmann-Lévy, 2018, 216 pages, 17 euros.

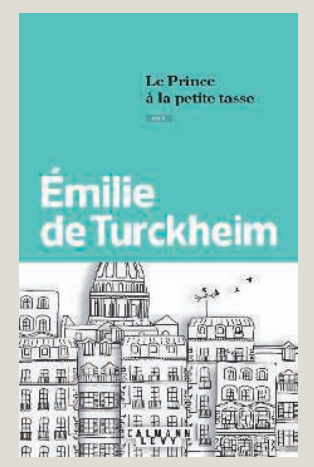

Voici un récit surprenant sur une expérience vraie, réelle, vécue. Accueillir un migrant chez soi, au sein de sa famille, c'est non seulement faire preuve de générosité ou être à l'écoute de l'Autre, c'est savoir ce qu'on veut réellement: "écrire ou accueillir, il faut choisir». C'est surtout s'adapter à l'autre: «Si Reza vient vivre à la maison, alors il faut que la maison, elle aussi, soit prête à vivre avec Reza.» C'est se poser des questions sur ses propres valeurs, ses engagements. C'est les mettre à l'épreuve, car accueillir est «un voyage joyeux».
Cette aventure humaine débute ainsi: «Un jour, j'ai dit: "Ils sont des milliers à dormir dehors. Quelqu'un pourrait habiter chez nous, peut-être?" Et Fabrice a dit: "Oui, il faudra juste acheter un lit." Et notre fils Marius a dit: "Faudra apprendre sa langue avant qu'il arrive." Et son petit frère Noé a ajouté: "Faudra surtout lui apprendre à jouer aux cartes, parce qu'on adore jouer aux cartes, nous!"» Commence alors un temps de préparation: acheter un lit, installer les deux enfants dans la même chambre. "Les enfants avaient repéré l'Afghanistan sur la carte du monde épinglée au mur de leur chambre. Noé m'avait dit: "Je te préviens, maman, c'est super loin!"» Ce temps de l'accueil impose de se préparer à l'hospitalité, et cela va jusqu'à débarrasser son salon de toute photographie de femme nue pouvant heurter Reza:

"Je peux imaginer que Reza se sentira mal à l'aise, et peut-être blessé, devant ce ballet de femmes nues. $)$

Accueillir d'accord, mais comment communiquer avec un réfugié qui ne parle pas le français? Comment se faire comprendre et comprendre l'autre? Comment éviter les approximations et les malentendus comme lorsque Reza assimile l'accent du Sud-Ouest à un dialecte: «Non, Reza, c'est pas un dialecte! C'est une façon de prononcer. C'est un accent. Par exemple, à Paris, on a un accent pointu. Avec mes mains, je forme un chapeau pointu, qui ne ressemble à rien et n'explique rien. On éclate de rire, conscients de ne pas réussir à se comprendre.»Et puis, un jour, cette phrase inattendue que prononce Reza: «Pardon pour toutes les fois je ne pas compris.»

Ce journal représente le point de vue de la famille, un point de vue inhabituel, original, mais qui laisse en suspens celui de Reza: "Qu'a ressenti Reza à la seconde où nous nous sommes rencontrés?» Car toute aventure prend fin un jour: «Reza s'en va. Daniel s'en va. [...] C'est l'heure. C'est vraiment l'heure.» En refermant ce beau récit, on le reprend du début pour mieux mesurer le chemin parcouru à cinq, réalisant que c'est possible, qu'une telle aventure humaine est possible.

N. J. 